\title{
Profiling of Nutritional and Health-Related Compounds in Developed Hexaploid Oat Lines Derivative of Interspecific Crosses
}

\author{
Rajae Manzali ${ }^{1, *}$, Abderraouf El Antari ${ }^{2}$, Ahmed Douaik $^{3}$, Mouna Taghouti ${ }^{4}$, Moncef Benchekroun ${ }^{1}$, \\ Mohamed Bouksaim ${ }^{4}$, Nezha Saidi ${ }^{5}$ \\ ${ }^{1}$ Departement of Biology, Health and Environnement, Hassan I University, Faculty of Sciences and Techniques, Settat, Morocco \\ ${ }^{2}$ RU Food Technology, INRA, Marrakech, Morocco \\ ${ }^{3}$ RU Environment and Conservation of Natural Resources, INRA, Rabat, Morocco \\ ${ }^{4}$ RU Food Technology, INRA, Rabat, Morocco \\ ${ }^{5}$ Research unit Plant Breeding, Conservation and Valorisation of Plant Genetic Resources, INRA, Rabat, Morocco \\ *Corresponding author: raja.manz@live.fr
}

\begin{abstract}
Physico-chemical, functional and antioxidant capacities of 26 oat (Avena sativa L.) lines and cultivars were investigated. The results showed that the contents were considerably variable within samples, starch concentration $(44,83-63,79 \%)$, carbohydrate $(42,08-62,65 \%)$, protein $(9,67-17,44 \%)$, fat $(3,06-10,96 \%)$, $\beta$-glucan $(1,37-6,05 \%)$ and ash $(1,22-5,38 \%)$. The analysis of fatty acids composition indicated that, palmitic acid, oleic acid, linoleic acid, stearic acid and linolenic were the major fatty acids in oat lipids, and that the contents of total UFA in assessed material varied between72, 29-80,11\%. Moreover, the phenolic content varied from 23,1 to 56,5 mg $\mathrm{GAE} / 100 \mathrm{~g}$, carotenoids content range from 0,98 to $4,34 \mu \mathrm{g} \beta$-carotene equivalents/g and antioxidant activity, evaluated as DPPH radical scavenging activity, from 12,2 to $46,7 \%$. The Protein profiles showed nearly identical nature of electrophoresis patterns, indicating no eventual change in protein quality. It could be concluded here that the flour of issue from these cultivars provide health benefits and high added value, if included as an ingredient for making new functional food products to meet the demands of health conscious generation.
\end{abstract}

Keywords: oats, fatty acids, starch, gluten free, proteins, $\beta$-glucan, antioxidant capacity

Cite This Article: Rajae Manzali, Abderraouf El Antari, Ahmed Douaik, Mouna Taghouti, Moncef Benchekroun, Mohamed Bouksaim, and Nezha Saidi, "Profiling of Nutritional and Health-Related Compounds in Developed Hexaploid Oat Lines Derivative of Interspecific Crosses." International Journal of Celiac Disease, vol. 5, no. 2 (2017): 72-76. doi: 10.12691/ijcd-5-2-6.

\section{Introduction}

Oat is an important crop that has gained a wide interest owing to its value-added applications. Oat grains are a rich source of protein with substantial levels of essential amino acids, soluble fiber, several natural antioxidants and essential minerals [24]. All these nutrients and compounds possess potential properties and health benefits [6]. This cereal contain also high amounts of lipids compared with other cereal seeds, with high content of unsaturated fatty acids [10]. These components determines in large measure its technological properties and functionalities in processing [28,29]. Additionally, many compounds in oat grains are known to exert antioxidant activity and thus oat flour has good antioxidant capacity that contribute to the food stability and protection [5]. The nutritional attributes, in particular these derived from $\beta$-glucan and protein concentrations as well as fatty acids profile promote not just its consumption but its integration in medicinal and pharmacological purposes [11]. This high dynamic in oat market promote also the formulation of new oat derived products and is accompanied with the appearance of new cultivars every year. Production of high quality oat grain is dependent on the planting of high quality seed [7]. In response, oat breeding efforts continue to strive to provide improved quality oats for evolving markets. Selection of best cultivars is dedicated by the definition of exact specifications depending on the intent application. As the requirements for quality vary with the end use of the crop. Leonova et al reported that interspecific hybridization can be regarded as an efficient source for improving oat grain quality and increasing the nutritional value of the crop for human consumption [14]. And, that the development of oat cultivars with high quality traits in the groat, can be achieved by utilizing wild species in breeding procedures. Two species of wild oats tetraploid $A$. murphyi and $A$. magna were utilized owing to their exceptional composition, to introduce new genetic diversity into the oat gene pool, in order to select the most interesting cultivars. Noteworthy that, both species are well adapted to the Moroccan climate and are genetically similar to $A$. sativa [16]. Therefore, the aim of the present study is to highlight groat composition of improved oat lines issues from interspecific crosses, investigate the fatty acids 
profiles and based on their nutritional value select performing cultivars. So far, limited research has been carried out on the correlations between fatty acids profiles and the contents of biologically active compounds in oats. Thus, multivariate data analysis was used to the developed oat lines in an attempt to map the main variations in fatty acids composition, nutrients concentrations and the possible relations between the analyzed variables. This knowledge is relevant in oat breeding and for selection of cultivars when aiming at specific compound/profiles for specific food, feed or industrial applications and innovations.

Therefore, the aim of the present study is to highlight groat composition of improved oat lines issues from interspecific crosses, investigate the fatty acids profiles and based on their nutritional value select performing cultivars. So far, limited research has been carried out on the correlations between fatty acids profiles and the contents of biologically active compounds in oats. Thus, multivariate data analysis was used to the developed oat lines in an attempt to map the main variations in fatty acids composition, nutrients concentrations and the possible relations between the analyzed variables. This knowledge is relevant in oat breeding and for selection of cultivars when aiming at specific compound/profiles for specific food, feed or industrial applications and innovations.

\section{Materiel and Methods}

\subsection{Plant Material}

The used material is made of six Moroccan hexaploid oat (five cultivars of $A$. sativa $\mathrm{L}$. and one cultivar of A.nuda, all registered in the Official Catalogue), two accessions of tetraploid oat $A$. magna, two accessions of tetraploid oat $A$. murphyi, and sixteen cutivars of improved hexaploid oat of $A$. sativa, derivatives from interspecific crosses previously achieved between Moroccan hexaploid oat cultivars of $A$. sativa and wild accessions of tetraploid oat $A$ magna murphy and Terrell and A. murphyi Ladiz, respectively. Samples were obtained from the National Institute for Agricultural Research (INRA), Rabat, Morocco, Research Unit of Plant Breeding, Conservation and Valorization of plant genetic resources.

\subsection{Methods}

Samples for chemical determinations were ground using an ultra-centrifungal mill (UDY Cyclone) Ground samples were analyzed for: Ash [2], Gluten content [12], crude protein by macro-Kjeldahl $\mathrm{N}$ analyses [3]; starch (STA) as descriped by Lim [15]; ß-glucan (GLU) using the Megazyme (1-3)(1-4) Beta-D-Glucan Assay Kit, according to McCleary [20] and fat content (FC) with a soxhlet apparatus [2]. The lignin content (ADL) was determined with an FIBERTEC Fiber Analyzer, according to the detergent fibre system [27]. Phenolics were determined according to the Folin-Ciocalteau procedure [25], carotenoids were assessed using the method of Abdel et al [1] and antioxidant activity by the DPPH $\bullet$ method [22].
The fatty acid profile was determined with a direct method of extraction and methylation according to Dhanda [8] to obtain fatty acid methyl esters (FAME). The fatty acid composition of FAME was analyzed in a capillary column Varian CP-Select CB for FAME, with dimensions of $50 \mathrm{~m} \times 0.25 \mathrm{~mm} \times 0,39 \mathrm{~mm}$. The initial temperature of $190{ }^{\circ} \mathrm{C}$ was maintained for $10 \mathrm{~min}$, increased subsequently at a rate of $4{ }^{\circ} \mathrm{C}$ min-1, Nitrogen was used as a carrier. The injector and detector temperatures were set at 230 and $250{ }^{\circ} \mathrm{C}$, respectively. Fatty acids were identified by contrast of their retention times against the fatty acids methyl standard. The extraction and separation of oat total protein using SDSPAGE electrophoresis, were developed following the method of Mikola [21].

\subsection{Statistical Analysis}

Results are expressed as mean values \pm standard deviation of three separate determinations in each extract and are reported on a dry matter basis. The significant differences between means were calculated by ANOVA using Tukey's studentized range test at $\mathrm{P}<0.05$. Correlations between parameters were examined by Pearson's correlation test.

\section{Results and Discussion}

The intact groats of oat genotypes selected for this study were analyzed for the main grain constituents. Table 1 shows the mean values and standard deviations across genotypes for all traits.

Certain lines contains much higher fat concentrations of up to $10,96 \%$ than other cultivars. Oat grain is also a concentrated source of carbohydrates, ranging from $42,08 \%$ to $62,65 \%$, as starch is the major storage component in oat. Oats are the cereals having the highest content of soluble fibers, it was found to be between $3 \%$ and $6 \%$. This trait, followed the same tendency as fat content with a considerable variation within cultivars and thus, would be useful for different purposes.

High antioxidant activities were recorded for most lines. This antioxidant activity may represent a value-added substance from oat improved lines that may have varied application in stabilizing the flour issue from rich lipid lines for the formulation of based food products.

Table 1. Values for health-related nutritional compounds of oat improved lines

\begin{tabular}{|l|c|c|c|}
\hline Parameters & Range & Average & Stdev \\
\hline Protein content (\%) & $9,67-17,44$ & 12,25 & 1,46 \\
\hline B-glucan content (\%) & $1,37-6,05$ & 3,39 & 1,07 \\
\hline Ash content (\%) & $1,22-5,38$ & 3,59 & 0,83 \\
\hline Starch content (\%) & $44,83-63,79$ & 57,2 & 1,34 \\
\hline Carbohydrates content (\%) & $42,08-62,65$ & 52,29 & 4,31 \\
\hline Fat content (\%) & $3,06-10,96$ & 6,42 & 1,83 \\
\hline Carotenoids content (\%) & $0,98-4,34$ & 2,82 & 0,68 \\
\hline Phenolics content (\%) & $23,1-56,5$ & 36,68 & 8,51 \\
\hline Gluten content (\%) & 0 & - & - \\
\hline Antioxidant activity (\%) & $12,2-46,7$ & 16,65 & 1,32 \\
\hline
\end{tabular}


Among the compositional components, protein concentration is ranked highly in importance because of its nutritional significance. It was shown in our samples that oat proteins, called avenins, do not contain any traces of gluten proteins. Thus, these lines may be recommended for patients who are intolerant to gluten proteins from wheat, rye, and barley.

High protein content in cereals is a desirable character when developing cultivars with improved nutritional value. Efforts to genetically improve oat protein concentration have indicated relatively high heritability of this trait. Nevertheless, the improvement must ensure the preservation of the protein quality and stability of developed lines.

Electrophoresis patterns have been used for grain protein comparison. The total protein electrophoresis patterns of the 24 samples were carried out (Figure 1).

The results for oats proteins showed that, the majority of the bands have low MWs, referring to that of globulin, glutenin and albumin. Oat migration profile is clustered mainly into two classes. The first group of bands around $30 \mathrm{kDa}$ and the second observed between $39 \mathrm{kDa}$ to 46 $\mathrm{kDa}$. The faster ones being fainter, detercted betwixt 46 and $68 \mathrm{kDa}$, were better marked in tetraploid accessions than in hexaploid cultivars. SDS-PAGE gels suggest that there are similar polypeptides components in the storage proteins of these cultivars.

Generally, a similarity index (SI) could be used to compare band variations between species, the higher the index is, the higher the level of similarity between species or within a group of cultivars [23]. This Index is calculated as:

$$
S I=\frac{\text { Number of common bands }}{\text { Total number of bonds }} \times 100 .
$$

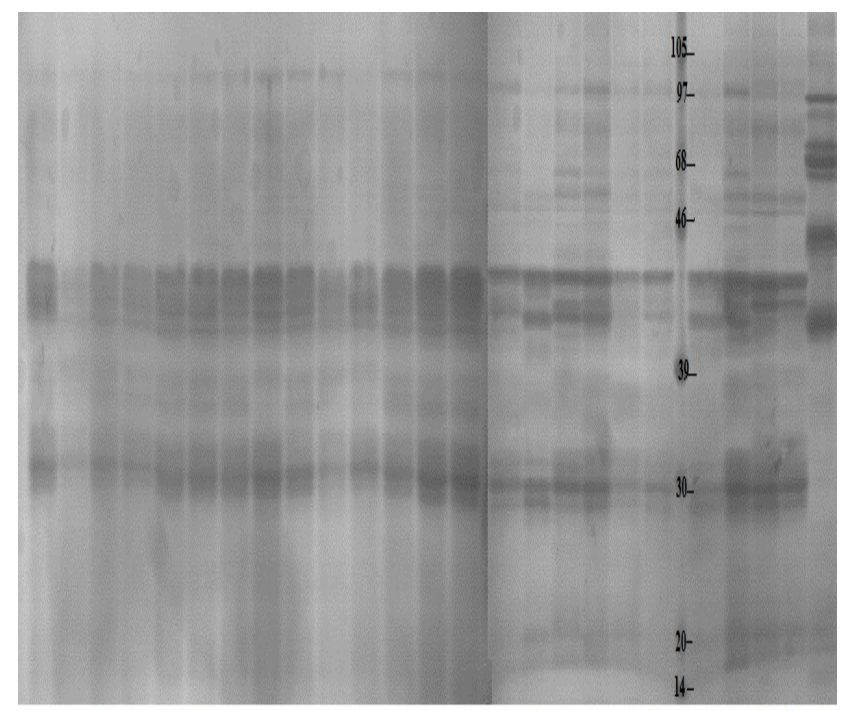

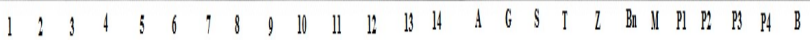

Figure 1. Total protein extracts from improved oat lines and cultivars separated by SDS-PAGE gels and stained with Coomassie Blue. Lanes were obtained from three SDS-PAGE gels run at the same time. The Numbers from 1 to 14 are the developed lines; A, G, S, T, Z and Bn refer to the oat varieties; the lane $\mathrm{M}$ contains the mol wt markers; lanes $\mathrm{P}$ are the tetraploid accessions, and B refer to a Barley variety. Numbers in the lane $\mathrm{M}$ refer to the molecular mass of the marker and major oat seed polypeptides in $\mathrm{kDa}$
In this study, a similarity index of $79,3 \%$ was obtained and this value confirm how closely related the improved lines are to each other and to the four tetraploid accessions.

Interest in oat lipids has a number of aspects metabolic energy for animal feed, the effects of lipids on functionality for processing and lipid stability and storage in food products. In our experiment, various fatty acids were found in all genotypes: myristic $(\mathrm{C} 14: 0)$, palmitic (C16:0), palmitoleic (C16:1), heptadecenoic (C17:0), estearic (C18:0), oleic (C18:1), linoleic (C18:2), linolenic (C18:3); arachidic (C20:0), eicosenoic (C20:1), henicosenoic (C21:0), eicosatrienoic (C20:3), eicosapentoenoic (C20:5).

Therefore in Table 2, we report the most relevant fatty acids accounting for more than $96 \%$ of total fatty acids; prevailing palmitic, oleic and linoleic acids with more than $90 \%$ of total. Palmitic acid $(15-21 \%)$ was the main saturated fatty acid. High levels of oleic and linoleic acids were also found in our experiment ranged from $29 \%\left(\mathrm{~F}_{10-1}\right.$ (murxsat)) to $40 \%$ (Tissir) and from $32 \%$ ( $\mathrm{F}_{11-4}$ (magxsat)) to $43 \%\left(\mathrm{P}_{1-6} A\right.$. magna accession $)$ respectively. These three fatty acids were detected in every study on oat samples. We also found substantial amounts of estearic (1,92-4,6\%), linolenic $\quad(0,74-5,84 \%)$, arachidic $\quad(0,4-3,14 \%)$ and eicosenoic $(0,4-6,07 \%)$ in most samples. Showed data indicated significant variations of the proportions of palmitic, oleic and linoleic acids. The compositions of fatty acids observed in oat cultivars were in agreement with previous results on oat grain [13]. However, the levels of estearic and oleic acids were much higher and comparable to Martinez et al [19] reports. Whereas palmitic, linoleic and linolenic acids proportions were in accordance with the research done by Leonova et al [14].

Figure 2 indicates that there were significant $(p<0.01)$ differences between the oat cultivars with respect to their fatty acids composition and distribution (saturated and unsaturated). Total saturated fatty acid contents ranged from 19,89 to 27,71 whereas total unsaturated fatty contents acids ranged from 72,29 to $80,11 \%$ and consisting mainly of equal amounts of oleic and linoleic acids. The proportion of unsaturated fatty acids was higher in the samples: $\mathrm{F}_{11-8}$ (magxsat), Amlal and $\mathrm{P}_{1-6}$ (A.magna accession).

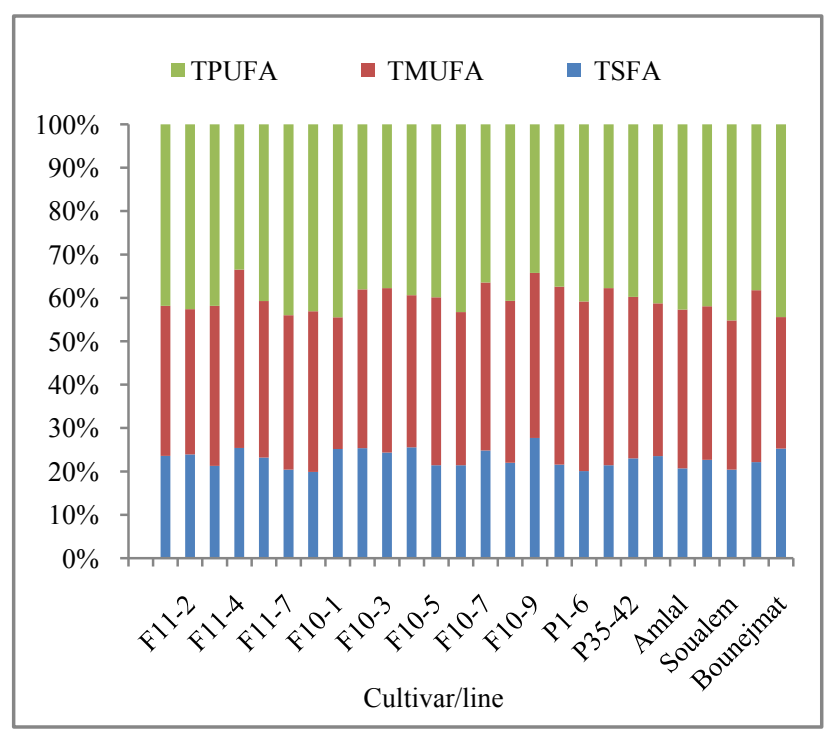

Figure 2. Proportions of fatty acids groups in oat lines and cultivars 
Table 2. Fatty acid composition of oat improved lines

\begin{tabular}{|c|c|c|c|c|c|c|c|c|}
\hline \multirow{2}{*}{ Cultivars / line } & \multicolumn{8}{|c|}{ Fatty acids \% } \\
\hline & C 14:0 & C 16:0 & C 18:0 & C 18:1 & C 18:2 & C $18: 3$ & C 20:0 & C 20:1 \\
\hline$F_{11-1}^{\dagger}$ & 0,75 & 18,10 & 3,55 & 34,12 & 40,81 & 1,00 & 1,20 & 0,47 \\
\hline$F_{11-2}^{\dagger}$ & 0,61 & 18,32 & 2,93 & 33,05 & 41,34 & 1,28 & 2,04 & 0,44 \\
\hline $\mathbf{F}_{11-3}^{\dagger}$ & 0,80 & 17,29 & 2,75 & 35,45 & 40,57 & 1,28 & 0,42 & 1,45 \\
\hline$F_{11-4}^{\dagger}$ & 0,26 & 20,60 & 3,44 & 38,97 & 32,50 & 0,96 & 1,11 & 2,16 \\
\hline $\mathbf{F}_{11-5}^{\dagger}$ & 0,41 & 18,95 & 2,61 & 34,38 & 39,60 & 1,15 & 1,21 & 1,69 \\
\hline $\mathbf{F}_{11-7^{\dagger}}^{\dagger}$ & 0,61 & 16,69 & 3,12 & 35,18 & 42,43 & 1,57 & 0,00 & 0,40 \\
\hline$F_{11-8}^{\dagger}$ & 0,50 & 15,69 & 3,29 & 33,76 & 37,25 & 5,84 & 0,40 & 3,27 \\
\hline $\mathbf{F}_{10-1}{ }^{\ddagger}$ & 0,72 & 20,87 & 2,86 & 29,40 & 42,44 & 2,02 & 0,73 & 0,96 \\
\hline$F_{10-2}{ }^{*}$ & 0,54 & 20,56 & 3,17 & 35,35 & 37,21 & 0,81 & 1,08 & 1,28 \\
\hline$F_{10-3}{ }^{*}$ & 0,60 & 18,72 & 2,46 & 32,51 & 36,47 & 1,28 & 2,55 & 5,40 \\
\hline$F_{10-4}{ }^{*}$ & 0,63 & 18,90 & 4,60 & 33,63 & 38,15 & 1,23 & 1,43 & 1,42 \\
\hline$F_{10-5}{ }^{*}$ & 0,72 & 16,85 & 2,14 & 34,15 & 37,57 & 2,28 & 1,69 & 4,60 \\
\hline$F_{10-6}{ }^{*}$ & 0,58 & 17,63 & 3,21 & 34,82 & 41,79 & 1,49 & 0,00 & 0,48 \\
\hline $\mathbf{F}_{10-7^{*}}$ & 0,52 & 20,73 & 2,92 & 37,27 & 35,58 & 0,88 & 0,67 & 1,42 \\
\hline$F_{10-8}{ }^{*}$ & 0,48 & 17,62 & 3,47 & 36,49 & 38,89 & 1,78 & 0,42 & 0,86 \\
\hline$F_{10-9}{ }^{\ddagger}$ & 0,56 & 21,74 & 4,41 & 35,91 & 33,18 & 1,05 & 1,00 & 2,14 \\
\hline$P_{1-1}^{*}$ & 0,33 & 18,01 & 2,83 & 34,07 & 40,51 & 1,40 & 1,48 & 1,37 \\
\hline$P_{1-6}^{*}$ & 0,42 & 17,16 & 2,82 & 31,84 & 43,40 & 1,79 & 0,00 & 2,57 \\
\hline $\mathbf{P}_{50-52}{ }^{*}$ & 0,55 & 18,47 & 2,05 & 38,78 & 37,44 & 0,81 & 1,08 & 0,81 \\
\hline $\mathbf{P}_{35-42}{ }^{*}$ & 0,63 & 21,11 & 3,50 & 30,01 & 42,58 & 1,83 & 0,00 & 0,33 \\
\hline Tissir $^{\nabla}$ & 0,62 & 18,74 & 2,05 & 40,03 & 36,66 & 0,74 & 0,17 & 1,00 \\
\hline Amlal $^{\nabla}$ & 0,43 & 16,95 & 2,71 & 32,99 & 39,36 & 1,49 & 0,00 & 6,07 \\
\hline Zahriv $^{\nabla}$ & 0,32 & 16,76 & 3,07 & 39,18 & 36,74 & 1,00 & 1,28 & 1,64 \\
\hline Soualem $^{\nabla}$ & 0,69 & 17,27 & 1,92 & 33,24 & 37,11 & 2,68 & 3,14 & 3,95 \\
\hline Ghali $^{\nabla}$ & 0,35 & 19,49 & 2,64 & 32,97 & 40,01 & 1,26 & 1,03 & 2,24 \\
\hline Bounejmat $^{\nabla}$ & 0,63 & 17,99 & 2,06 & 34,63 & 40,59 & 2,11 & 0,00 & 1,99 \\
\hline
\end{tabular}

Fatty acids: $\mathrm{C} 16: 0$ : palmitic; $\mathrm{C} 18: 0$ : estaric; $\mathrm{C} 18: 1$ : oleic; $\mathrm{C} 18: 2$ : linoleic; $\mathrm{C} 18: 3$ linolenic; $\mathrm{C} 20: 1$ : eicosenoic; $\mathrm{C} 21: 0$ : henicosenoic; C20:5: eicosapentaenoic.

$\dagger$ (A. sativa $x$ A. magna) $x$ A. sativa

(A. sativa $x$ A. murphyi) $x$ A. Sativa

*Tetraploïde accessions

$\nabla$ Varieties.

In order to compare the potential impact of fat on human health Scientifics often used fatty acids ratio calculated as PUFA/SFA, this ratio must be higher than 0,4 . The evaluation of ratios showed that ratio PUFA/SFA of analyzed oat samples varied from 2,61 to 4,03, it was 2 times higher than reported values by Sterna et al [26].

Correlation analysis and visualized relations between nutritional quality traits had revealed a weak correlation between the following parameters: Fat content and fatty acids levels, protein and starch contents. While for Protein and fat content a negative correlation were observed. An unexpected result was the positive correlation between protein and ash contents. A high and significant correlation has been found between total phenolics and carotenoids contents, and antioxidant activity in all lines and cultivars.

Interestingly, it was reported that the essential macro and micronutrients, along with the phytonutrients present in oat groat, synergistically contribute to its beneficial effects.
And in another study involving the health claims associated with whole grains consumption, that habitual consumers of primarily whole grain flour products, had an important role in lowering the risk of chronic diseases, such as coronary heart disease, diabetes, cancer, and also contribute to body weight management and gastrointestinal health.

The chemical analysis of oat samples demonstrated the rich protein and soluble dietary fiber content of Moroccan accessions, varieties and developed lines. Additionally, the levels and degree of unsaturation of the oat total fatty acids was higher in this collection compared with similar research carried out on oat lipids [4]. Moreover, results demonstrated that studied lines have, besides their nutritional value, higher phytonutrients contents and antioxidant activities.

Positively in this experiment, there were nutritional differences in nutrients contents, among oat genotypes, suggesting an extent of their specific applications. The outcomes of this experiment and these generated from 
previous studies $[17,18]$ on theses lines indicated that, the lines $\mathrm{F}_{10-1}$ (magxsat) and $\mathrm{F}_{11-4}$ (murxsat) were highlighted with exceptional grain quality potential and elevated concentrations of starch, protein and $\beta$-glucan contents. These lines contain also higher levels of UFAs and phenolics compared with the rest of samples. While the line $\mathrm{F}_{11-8}$ (murxsat), with high lipid content and consisting of minor amounts of saturated fatty acids, remains a potential oil crop.

In this study, the four wild species accessions have shown a strong potential approved by their nutritional composition and fatty acids profiles, suggesting their eventual contribution in the development of the improved hexaploid lines, as donors of genes of interest. In Morocco, oat cereal is undervalued in comparison to wheat and barley. Though such cultivars and lines with these versatile components may enhance its economic value.

\section{Conclusion}

Oat groat compositional components of nutritional and industrial significance include starch, protein, fatty acids, soluble fiber $\beta$-glucan and antioxidant activity were evaluated and showed consistency between components contents and associated profiles. Strong genotypic differences were observed in groat composition across the samples. The main fatty acids present in oats lines and cultivars are (MUFA, C18:1) and (PUFA, C18:2), followed by saturated fatty acid (C16:0). Results of evaluation $\mathrm{P} / \mathrm{S}$ for health account, showed that the ratio varied from 2,61 to 4,03 . In addition, these oats lines fit into a gluten-free cereal group unlike wheat, rye and barley. Thus is accepted as safe for celiac disease patients. The presence of many health-promoting compounds makes those lines interesting crops to be applied to functional foods and special diets directly as part of the daily intake of the consumers.

\section{References}

[1] Abdel-Aal, E. S. M., Young, J. C., Rabalski, I., Hucl, P., \& Fregeau-Reid, J. Identification and quantification of seed carotenoids in selected wheat species. Journal of agricultural and food chemistry. 2007; 55(3): 787-794.

[2] American Association of Cereal Chemists, Approved Methods, 8 ed., Saint Paul, 1983.

[3] Association of Official Analytical Chemists, Methods of analysis for nutrition labeling, Airlington, USA, 1993.

[4] Banas, A., Debski, H., Banas, W., Heneen, W. K., Dahlqvist, A., Bafor, M., et al. Lipids in grain tissues of oat (Avena sativa): differences in content, time of deposition, and fatty acid composition, Journal of Experimental Botany, 58(10). 2463-2470. 2007.

[5] Brindzova, L., Certik, M., Rapta, P., Zalibera, M., Mikulajova, A., and Takacsova, M. Antioxidant activity, $\beta$-glucan and lipid contents of oat varieties, Czech journal of food sciences, 26(3). 163-173. 2008.

[6] Broeck, H. C. V., Londono, D. M., Timmer, R., Smulders, M. J., Ludovicus, J. W. J., \& Vander Meer, I. M. Profiling of Nutritional and Health-Related Compounds in Oat Varieties, Foods, 5(1). 2. 2015.

[7] Daglioglu, O., Tasan, M., and Tunçel, B. Determination of fatty acid composition and total trans fatty acids in cereal-based Turkish foods, Turkish Journal of Chemistry, 26(5). 705-710. 2002.
[8] Dhanda, R. K. Fatty acid composition in diverse oat germplasm. Doctoral dissertation. 2011.

[9] Doehlert, D. C. Quality improvement in oat, Journal of crop production, 5(1-2). 165-189. 2002

[10] Halima, N. B., Saad, R. B., Khemakhem, B., Fendri, I., and Abdelkafi, S. Oat (Avena sativa L.): Oil and Nutriment Compounds Valorization for Potential Use in Industrial Applications, Journal of Oleo Science, 64(9). 915-932. 2015.

[11] Hosseinian, F., Oomah, B. D., and Campos-Vega, R. (Eds.). Dietary Fibre Functionality in Food and Nutraceuticals: From Plant to Gut. John Wiley \& Sons. 2016.

[12] I.S.1155, (1968). Specification for wheat Atta / I.S.I. Hand book of food analysis pp, 115.

[13] Justyna, R. K., Miskiewicz, K, Nebesny, E., and Makowski, B. Plant Lipids Science, Technology, Nutritional Value and Benefits to Human Health: Composition and functional properties of lipid components from selected cereal grains. Editors: Grazyna Budryn and Dorota Zyzelewicz. 2015: 119-145.

[14] Leonova, S., Shelenga, T., Hamberg, M., Konarev, A. V., Loskutov, I., and Carlsson, A. S. Analysis of oil composition in cultivars and wild species of oat (Avena sp.), Journal of agricultural and food chemistry, 56(17). 7983-7991. 2008.

[15] Lim, W. J., Liang, Y. T., Seib, P. A., and Rao, C. S. Isolation of oat starch from oat flour, Journal of Cereal Chemistry, 69(3) 233-236. 1992.

[16] Loskutov, I. G. Interspecific Crosses in the Genus Avena L, Russian Journal of Genetics, 37(5), 467-475. 2001

[17] Manzali, R., Bouksaim, M., Bendou, M., Zouahri, A., Benchekroun, M., Douaik, A., and Saidi, N. Evaluation of Technological Potential of New Developed Moroccan Hexaploid Oat Lines, International Journal of Engineering Research and Technology, 3(7), 1760-1767. 2014.

[18] Manzali, R., Benchekroun, M., Douaik, A., Ait ellalia, W., Bouksaim, M., and Saidi, N. Improving Groat beta-Glucan Content of Developed Hexaploid Oat Lines Derivative of Interspecific Crosses. Journal of Biology Agriculture and Healthcare, 6(12), 34-41. 2016.

[19] Martinez, M. F., Arelovich, H. M., and Wehrhahne, L. N. Grain yield, nutrient content and lipid profile of oat genotypes grown in a semiarid environment, Field crops research, 116(1), 92-100. 2010.

[20] McCleary, B. V. Megazyme: Mixed-linkage beta-glucan assay procedure (McCleary method). Bray Business Park, Bray, 1-15. 2006

[21] Mikola, M. Electrophoretic studies on the endoproteinases of oat grain. University of Helsinki, Department of Food Technology. 2001.

[22] Ndolo, V. U., and Beta, T. Distribution of carotenoids in endosperm, germ, and aleurone fractions of cereal grain kernels, Food chemistry, 139(1), 663-671. 2013

[23] Ochuodho, J. O., Modi, A. T., and Beukes, M. Accumulation of seed storage proteins in Cleome gynandra L. and Brassica kaber L, South African Journal of Botany, 72(2), 238-244. 2006.

[24] Singh, R., De, S., and Belkheir, A. Avena sativa (Oat), a potential neutraceutical and therapeutic agent: an overview, Critical reviews in food science and nutrition, 53(2), 126-144. 2013.

[25] Singleton, V. L., Orthofer, R., and Lamuela-Raventos, R. M Analysis of total phenols and other oxidation substrates and antioxidants by means of folin-ciocalteu reagent, Methods in enzymology, 299, 152-178. 1999.

[26] Sterna, V., Zute, S., Brunava, L., and Vicupe, Z. Lipid composition of oat grain grown in Latvia. In 9th Baltic Conference on Food Science and Technology "Food for Consumer WellBeing". p. 77. 2014

[27] Van Soest, Robertson, P.J. J.B. and Lewis, B.A. Methods for dietary fiber, neutral detergent fiber, and non starch polysaccharides in relation to animal nutrition, Journal Dairy Science, 74, 3583-3597. 1991.

[28] Zhang, N., Li, D., Zhang, X., Shi, Y., and Wang, H. Solid-state fermentation of whole oats to yield a synbiotic food rich in lactic acid bacteria and prebiotics, Food and function, 6(8), 2620-2625. 2015.

[29] Zhou, M., Robards, K., Glennie-Holmes, M., and Helliwell, S. Oat lipids, Journal of the American Oil Chemists' Society, 76(2), 159169. 1999. 